Original Article

\title{
What does the app want? \\ A psychoanalytic interpretation of dating apps' libidinal economy
}

\author{
Carolina Bandinelli ${ }^{\mathrm{a}, *}$ and Arturo Bandinelli ${ }^{\mathrm{b}}$ \\ aniversity of Warwick, Coventry, UK. \\ E-mail: carolina.bandinelli@warwick.ac.uk \\ birbeck, University of London, London, UK. \\ E-mail: abandi01@mail.bbk.ac.uk \\ *Corresponding author.
}

\begin{abstract}
In this article, we take dating apps as a case study to tackle the question of desire and enjoyment in contemporary society. Moving away from an instrumental conception of digital media, we focus on their (mis)functions and the related (dis)satisfactions. We argue that dating apps' key function and significance is not that of offering a means through which to find a potential partner, but rather of engaging the subject's desire without the need for an actual relationship with another person. Applying Lacanian theory to the analysis of empirical data, we dwell on the microphysics of enjoyment of dating apps to analyse the ways in which they activate, exploit and turn the subject's desire. We maintain that dating apps entail a libidinal economy that operates independently of the app's obvious function of connecting individuals: they act seductively, engaging the subject's desire in a pulsating dynamic of loss and gain, promise and frustration, thus becoming an affective object in their own right and offering a way for the subject to cope with the demand to enjoy typical of late capitalism. In a cultural atmosphere in which having a vibrant dating life becomes an imperative, thus foreclosing the space for desire to emerge, dating apps can be a way to respond to such injunctions without confronting the anxiety of an embodied encounter. Psychoanalysis, Culture \& Society (2021) 26, 181-198. https://doi.org/10.1057/ s41282-021-00217-5; published online 19 April 2021
\end{abstract}

Keywords: dating apps; libidinal economy; Lacan; enjoyment; desire 


\section{Introduction}

Digital societies are particularly distinguished by the emergence of new technologies of romance and sexuality; namely, dating apps. These have arguably contributed to a resignification of the rituals, grammar and values of romance, and constitute an object people relate to and rely on to an ever more significant degree. Previously socially stigmatised, online dating has now become not only largely acceptable but increasingly popular amongst urban youth in big cities. Recent statistics report that about 196 million adults use them, with people aged 18 to 29 being the largest population segment (Statista, 2020).

While it would be naïve to claim that dating apps have revolutionised our understanding of love and sexuality, we are witnessing a digital remediation of these domains, which is producing new codes to (re)negotiate romance. Dating apps' affordances and narratives remediate specific rituals of courtship, producing new practices, such as swiping, liking, matching and texting, and a related etiquette, or grammar, with specific questions attached to it: e.g. What kind of profile picture and bio is the right one? What kind of opening message? This is an evolving field which sees users trying to figure out how to deal with the techno-social milieu produced by the app itself (Ansari and Klinenberg, 2015; Ellison et al., 2011; Heino et al., 2010; Ranzini and Lutz, 2017).

In what follows, we draw on the Lacanian understanding of desire and enjoyment to explore the subject's engagement with dating apps. This perspective allows light to be shed on the psychic and affective investment that is at stake in the ways in which we relate to digital technologies. It implies an understanding of dating apps and digital media in general - not as a means to achieve certain ends - but rather as libidinal objects in their own right, i.e. objects capable of interacting with one's desire and enjoyment to turn, activate, hijack and support them. Instead of privileging a perspective that looks at what users do with the app, we shift our attention to what the app does to and for its users. What we are interested in is neither a conception of dating apps as mediators that can incentivise or discourage romantic and sexual encounters, nor an empirical analysis of users' behaviours and motivations. Rather, we look at the microphysics of enjoyment as produced within the relationship between the subject and the app. To do so, we look at what happens when their most explicit use, i.e. meeting potential partners, is not at stake. We ask: How do dating apps work when they do not work? Tackling this question, we analyse dating apps' libidinal economy, i.e. the ways in which they participate in the (ideological/fantasmatic) regulation of the open and contingent relationship between desire and enjoyment, lack and excess, in a given social order.

This resonates with enquiries on the affective, social and ethical stance of the networked self and sociality, marked by the ambivalence between a narcissistic 
movement towards extreme individualisation and the political potential of multiplied opportunities for social connections (e.g. Flisfeder et al., 2016; Papacharissi, 2011; Davies et al., 2014; Turkle, 2011). This strand of research has mapped the multiple ways in which digital media can be used and misused to build or alienate social relations and identities (for two complementary perspectives on this matter, see for instance, boyd, 2014; Turkle, 2011). What remains partially underexplored, however, is the nature of our involvement with digital media not as remediators of social relationships but as objects that trigger a particular kind of affective and libidinal investment (there are exceptions; e.g. Bown, 2015; Johanssen, 2019; Deuze, 2011). These can be found beyond the explicit function of the medium, in between the big events of failure and achievement of a supposedly rational purpose.

By means of a Lacanian analysis of empirical data that frames them in relation to the demands of the 'society of enjoyment' (McGowan, 2004), we highlight three key characteristics of dating apps' libidinal economy: (a) dating apps allow the subject to cope with the anxiety deriving from injunctions to enjoy a 'dating life' whilst disseminating the very same injunctions; (b) through the match, dating apps offer a quantifiable and crystallised sign of the possibility of a (romantic and sexual) event by engaging the subject in a dynamic of loss and gain that produces a particular kind of (dis)satisfaction; and (c) in so doing, dating apps may end up occupying the position of an affective object in their own right, standing in for the sexual or romantic partner they are meant to procure us.

This article is structured as follows. Firstly, we contextualise our research within academic debates on subjective enjoyment and social demands. Secondly, we introduce our object of study, i.e. dating apps, drawing on recent literature on the topic in the fields of media, sociology and cultural studies. Then, we offer a brief methodological note. In the empirical sections, we give voice to the research participants exploring the microphysics of enjoyment in a way that distinguishes dating apps beyond their obvious function of organising a date.

\section{Love, Sexuality and Desire in the Society of Enjoyment}

Modern popular culture has typically associated romantic love and sexuality with the space of exceptionality and transgression, at least until the second half of the $20^{\text {th }}$ century. Western literature, from Shakespeare to Goethe, placed them outside of the boundaries of social and economic constraints (De Rougemeont, 1983). Romantic love, characterised by the co-presence of love and sexuality, was represented as radically uncompromising and thus a potential threat to the social order. But after the sexual revolution of the $70 \mathrm{~s}$ - as sociologists and cultural scholars have shown (Beck and Beck-Gernshein, 1990; Illouz, 2011; Giddens, 1992) - romantic love became embedded in the 
social order, yet without losing its absolute character. As a result, in late capitalism, the social demand has turned into one of combining true love with the most satisfying sexual life in a 'healthy' relationship. This, as Illouz (2011) pinpoints, puts the person in front of an unsolvable dilemma: that of holding together pure love, wild passion, and the shared duties and responsibilities that characterise a long-lasting relationship.

Such a conception of love gets intertwined with the discourse of neoliberalism, which offers 'freedom of choice' as the pivotal device for navigating the stormy water of romance (Bauman, 2003). The individual is free to choose, and obliged to choose freely, and, if they are good enough at choosing, they may respond adequately to the social demand to optimise their life to its maximum (Salecl, 2010). There is no more social order to blame if complete emotional and sexual fulfillment is unattainable, but rather an insufficiency in the ways in which we relate to ourselves and others (Frith, 2015; Illouz, 2011). The sociologist Lisa Wade (2017) offers an illustration of how demands to enjoy one's sexuality are experienced by young people in the US. In an empirical study on college students, she shows how hook-ups can be perceived less as a liberation than an injunction. What we seem to be confronted with is a society in which love and sex are no longer a dimension where social imperatives may be transgressed but rather one that requires conforming to them.

How should we interpret this shift? Psychoanalysis offers a way to conceptualise the relationship between social demands and subjective enjoyment which yet again moves beyond a simple dichotomy. Already with early Freud (1908/1959), we have a detailed interplay between the internalisation of civilisation's commands and the subject's sexual impulses. In particular, as Freud (1930/1961) develops his concept of the superego, he highlights that the latter does not simply signal the internalisation of a social imperative but is also traversed by sadistic drives. For the super-ego, no renunciation is ever enough. As McGowan (2016) points out as he traces this genealogy, certain FreudoMarxist authors (e.g. Marcuse, 1998; Reich, 1974) have somewhat simplified Freud's argument, reducing it to a battle between sexual instincts and social repression. What follows is the idea that sexual desire could finally be liberated (and capitalism overthrown) by lifting prohibitions.

From a Lacanian perspective, a limitation of this approach is that, whilst producing a critique of capitalist ideology, it focuses on its dissatisfactions rather than on how capitalism exploits and obfuscates the subject's desire: 'the problem [. . . ] is not that capitalism fails to satisfy but that it doesn't enable its subjects to recognize where their own satisfaction lies' (McGowan, 2016, p. 11). Because for Lacan the subject is ontologically lacking (i.e. lack is constitutive of subjectivity), the ultimate aim of desire is not the filling of one's lack by means of an object (this would ultimately imply the subject's annihilation) but rather its own (i.e. desire's) perpetual continuation. In this strict sense, desire is constitutionally dissatisfied, but, notwithstanding this 
structural condition - or because of if - the subject is able to 'enjoy' in the gaps and cracks brought about by the repetitive failures to actually attain its 'proper' object: the Lacanian object a.

Importantly, the object of fantasy, object $a$, should not be understood as a positive entity capable of filling one's lack. From the point of view of the symbolic, it is the logical operator of lack; from the point of view of the real, it is the entropic waste produced by discursive operations (Lacan, 2007). However, capitalism obfuscates the negative dialectic of the subject's relation to its object - i.e. it papers over object a's constitutive negativity by endlessly promising to fill the subject's lack (and grant total satisfaction) by means of commodity objects. As Vighi (2015) explains, 'the pervasive commodification of objet a turns the latter into a master-signifier, securing the ideological closure of the capitalist structure' (p. 10); this 'masterisation' of object a effectively renders it 'a cruel master demanding more and more obedience to "flat", repetitive and utterly anodyne forms of enjoyment' (p. 10).

Lacan conceives of enjoyment - what he calls jouissance, which is different from pleasure for the way it refers to a sexually charged, excessive bodily experience deeply intertwined with a degree of failure - as an inherently problematic domain, distinguished by a complex (and failed) relation between subject and the Other. Rather than understanding the super-ego simply as an agency urging the renunciation of one's impulses, Lacan (1999) claims it always also commands a certain modality of enjoyment. As such, it follows a perverse sadistic logic: 'Nothing forces anyone to enjoy except the super-ego. The superego is the imperative of Jouissance - Enjoy!' (p. 3).

Far from liberating our desires, late capitalism has thus turned enjoyment into a social injunction (McGowan, 2004; Žižek, 1997). In this sense, Žižek (2005) is right when he writes that 'the superego is the revenge that capitalises upon our guilt' (p. 69), for it does cash in on our failed attempts to be the happy, healthy and sexually active individuals we are supposed to be. This offers a useful framework to understand the key elements that characterise late capitalism's libidinal economy and how it plays with our desire. It is against this backdrop that we look at dating apps and try to establish a dialogue between Lacanian theories and current media and cultural studies on love and sexuality in digital societies.

\section{The Rise of Dating Apps}

Dating apps' reflexive narratives claim to provide an efficient solution to tackle the problem of freedom and abundance in the consumerist scene of romance, offering a set of tools to source and rank potential partners. Overall, this narrative is procedural in kind, revolving around a form of solutionism (Morozov, 2013) that promises a maximisation of the possibilities to enjoy the 
realm of intimacy. Tinder's tagline 'Match Chat Date' suggests a simplification of the socio-cultural practice of dating, here turned into a 3-step procedure. In its very name, POF - Plenty of Fish - plays on the exponential augmentation of romantic possibilities. E-Harmony, with its successful slogan 'The Brain Behind the Butterflies', focuses on the utter rationalisation of an otherwise mysterious domain. Within this narrative, dating apps should enable a kind of optimisation of the dating process, making it 'easier' to navigate for users and enhancing their opportunities to meet 'suitable' partners.

However, scholarship in the field of media and communication has demonstrated that people use dating apps to fulfil needs that exceed the domain of emotional and physical intimacy. One piece of US-based research argues that 'although such apps are ostensibly to encourage people to meet, many people may be using them without such intentions' (Carpenter and McEwan, 2016, n.p.). These conclusions echo those of another study carried out in the Netherlands which shows that people use Tinder for a range of reasons, from 'entertainment to ego-boost, to relationship seeking' (Ward, 2016, p. 1). Sumter and Vandenbosch (2019) offer a classification of the motivations of dating apps' users in three broad categories, namely relational goals; entertainment goals; and intrapersonal goals. The last of these refers mostly to self-confidence and points to the ways in which dating apps' affordances allow users to act on themselves and receive feedback on these actions. From this viewpoint, dating apps act as a technosocial environment for the performance of the self, which impacts on the ways in which individuals perform their digital identities (Ellison et al., 2011; Gibbs et al., 2011).

Dating apps may leading to a specific perception of the self as a commodity (Heino et al., 2010) and of other users as potential deceivers (Sharabi and Caughlin, 2018). This assumes and produces a user who is to become very skilled at identifying deceptions (Sharabi and Caughlin, 2018; McGloin and Denes, 2016), handling rejections (De Wiele and Campbell, 2019) and managing aspirations (Ellison et al., 2011). At the same time, dating apps' affordances increasingly incentivise the entertainment component of swiping profiles, accentuating a marketised and gamified conception of dating (Zichermann and Cunningham, 2011; Heino et al., 2010; Hobbs et al., 2008).

This body of literature challenges a solutionistic and commonsensical understanding of dating apps as 'internet-based mobile applications [...] that people use for arranging intimate interactions with potential partners' (Comunello and Parisi, 2020) and suggests a more nuanced picture that encourages one to look at dating apps not only as mediating the relationship between people but also as an object with which we establish an affective relationship. Importantly, this comes before (logically and chronologically) the potential relationship between users themselves. As a matter of fact, first of all we relate to the apps' affordances, and these act on us in establishing what can 
and cannot be done. This questions the understanding of dating apps as mediators of romantic encounters; but it is consistent with the underlying logic of digital applications whose objective is that of retaining users. Dating apps, and apps in general, are 'sticky' (Kim et al., 2016), and this is to be found (also) beyond their most apparent function.

\section{Methodological Notes}

In this article, we offer an analysis of the empirical data that one of us (Carolina) collected over a period of 18 months from January 2018 to June 2019 as part of a piece of explorative qualitative research on the digital culture of love. This comprised ten in-depth interviews, five focus groups and a number of informal conversations. Additional data came from a two-month period of reflexive ethnography also conducted by Carolina. The participants were millennials living in Italy and the UK, the vast majority of whom were white, middle-class, well-educated, heterosexual, cis-gender individuals. While this is certainly a limitation of this research, it also allowed us to focus on the mainstream heteronormative use of dating apps. This is not a piece of comparative research: instead of being interested in contrasting and comparing how different contextual factors impact on the use of dating apps, we looked at the similarities between participants' experience (Beck and Beck-Gernsheim, 2008). The reader will notice that the main focus has been on Tinder. This reflects the popularity of this app amongst participants and its leading role in the market (Belton, 2018).

In what follows, we proceed by analysing empirical vignettes for how they shed light on the position of the subject vis-à-vis the social order. We do not use psychoanalysis to infer something about the unconscious of participants as singular individuals, nor did we use psychoanalytic methods to make them freely associate in interviews, as experimentally investigated, for instance, by Hollway and Jefferson (1997) and Johanssen (2019). Rather, we use psychoanalytical concepts as heuristic categories to interpret qualitative data. More specifically, Lacanian psychoanalysis provides us with a theory of subjectivity whereby the notions of desire and enjoyment can be mobilised to build a bridge between the dimension of individual experience and the discursive and libidinal functioning of social and political apparatuses (Hook, 2008; Parker, 2010). In this respect, this article contributes to the emerging field of psychosocial studies in that it regards social and psychic life as co-constitutive and inherently entangled (e.g. Frosh, 2010; Parker, 2010; Roseneil, 2006). 


\section{But the Apps Don't Work, or Do They?}

Most of the research participants - despite being habitual users of dating apps were not meeting many people. Many lamented what they seemed to consider an allegedly faulty aspect of dating apps: 'It doesn't work' they would typically say, referring to dating apps' algorithms. Others would blame themselves and their lack of self-branding skills. In some cases, perhaps more interestingly, participants were just not that interested in going out on a date, displaying what may at first seem a rather eccentric take on the matter. Overall, these observations reveal a picture in which getting a date is often perceived as difficult and not always desirable.

Sam, a British man in his late twenties living in London, had been on Tinder for a while, but had only very few dates - just two in the last year - neither of which resulted in a sexual or romantic involvement. Quite a few times, the dates he had arranged were bluntly cancelled. Once this had happened when, on his way to a date, he got an SMS asking, 'are you tall?' to which he replied, with admirable honesty, 'not particularly'. Elisa, an Italian woman based in London and the same age as Sam, recounted the same experience but with inverted roles, in which she cancelled a date having obtained more precise information about the height of her potential partner. Brad, a young man studying in the UK, confirmed that 'it's very hard to go out with someone you met on Tinder'. Jessica, a 35-year-old Italian woman living in London, has been using dating apps for over three years and disappointedly confirms that 'You don't find much there ... it's very difficult!'.

It comes as no surprise that users are often utterly frustrated with the app. 'It doesn't work!' claims Luca, an Italian man in his mid-twenties. Everyone who took part in this study at some point expressed the same view. Sam was puzzled. After a long open-ended interview, he wondered: 'Why are people on Tinder if they don't wanna meet?' Sam also turned the question on himself, noting that 'most of the time I use Tinder, when I am on the loo ... It is a way of just killing time, like doing something mindlessly, but also I feel I am doing something useful, I am being productive, in a sense.' The productivity of Tinder is related to its social function. As he put it: 'you feel like you are doing something you must be doing, looking for a partner, having a love life, being on the dating scene.'

The very simple act of installing Tinder on one's phone, setting up a profile and swiping allows individuals to signal their status on the dating scene. In psychoanalytic terms, using Tinder offers subjects a point of identification as desiring and desirable, hence opening up a space of enquiry into one's and the other's desire. Indeed, using dating apps, one can gossip, interpret, judge, imagine, wonder, fantasise. One can talk about one's achievements, interpret the messages, envisage possible scenarios, provide reassurances and unsolicited 
advice, even try to manipulate the other's feelings. Johanna, an undergraduate student, reports that her housemates talk about it 'all the time'. Elisa and her housemate Lawrence, an Italian man in his mid-thirties, would often organise a 'Tinder Salad' in their flat in London. Together with other friends, they would discuss how to improve their profiles, swipe together and even chat on behalf of one another.

These findings challenge any straightforward solutionistic understanding of dating apps, corroborating the findings of recent media studies on how dating apps' users' motivations exceed sexual and romantic intimacy (e.g. Ward, 2016; Sumter and Vandenbosch, 2019). Yet, we push this forward, arguing that the specific forms of leisure offered by the app in itself have a precise ideological connotation: allowing one to respond to the imperative of having a dating life by enabling a social - or, to put it psychoanalytically, fantasmatic performance of it. On the one hand, dating apps seem to offer a way to respond to the social demands of having a vibrant 'dating life'; on the other, they may be seen as a device implementing those same demands, leaving the subject with no excuse to disattend them. The user is caught up into a kind of feedback loop, a short-circuit, whereby cause and solution endlessly feed into each other.

\section{It's a Match!}

Even without meeting anybody, dating apps can offer their users a specific form of enjoyment. This can be found in what is arguably the most important thing that Tinder does without any direct contact with another human being: produce 'matches'. On Tinder, a match happens when two people reciprocally swipe right to signal that they fancy each other. Typically, the mobile phones of Tinder's users are full of matches; however, only a very small minority of them translate into a date or even a chat. This leads us to consider the match as not always or primarily instrumental to getting a date but rather as producing a form of satisfaction in its own right. Indeed, every participant mentions that getting matches makes them feel attractive, even if just for a few seconds. Amy, a young British woman based in London, recounts that she would use dating apps 'when feeling alone' just to get that 'confidence boost'.

Allison, a young British woman, put it clearly: 'I love to match and chat with strangers, but I would never meet a stranger!' Corrado, a 30-year-old Italian man living in Naples, has an analogous take: 'I like to test my attractiveness, getting as many matches as possible, but I would never go on an actual date with someone I met on Tinder!' In her reflexive journal, Sarah, a 20-year-old British woman, confessed that she uses the geo-localisation feature of Tinder to make sure that she matches with people who are far enough away to minimise 
the risk of 'meeting them', as 'how embarrassing would it be to meet someone you matched with?'

A match feels like a confidence-boost; it is a sign that the Other sees you and likes you, offering a form of recognition: I am or have something for the Other. Admittedly, it is ephemeral, but it is also replicable, so the sense of void that follows the fleeting sense of satisfaction is rapidly filled up again, however temporarily, with another match. Sandra, a 20-year-old British woman, puts it clearly: 'When you get a match you feel thrilled, and then the minute after you are empty again, but then another match comes... so it kind of works... .' Sandra's statement well describes the specific affective dynamic of matches: they are part of a sliding chain which pulsates between negativity (the absence of the match) and positivity (the match). Matches 'work' by themselves as replicable signs of likeability and indications of the possibility of a romantic encounter. Through this process, dating apps autonomously provide a form of a satisfaction deeply intertwined with a degree of failure and with the experience of the impossibility of completeness.

Importantly, matches can be produced ab limitum, the underlying utopia being that of providing potentially infinite opportunities: a desire that gets constantly re-ignited, regardless of its object, and at the same time negated, as the next profile picture appears on the screen. The match frames an unknown other - as well as ourselves - as a potential source of love, intimacy and sexuality. Matches are kept in the user's phone: crystallised, storable, countable. By means of the match, the app becomes the bearer of the horizon of possibilities that defines the evenemential encounter in its initial stages. The match is thus the technologically produced fixation of the possibility of an event, a techno-social object that refers to a specific temporality. With its repetitive and theoretically limitless offer, the app subsumes and re-mediates the infinite possible 'futures' that cause the subject's desire.

This replicates the logic of accumulation typical of late capitalism whereby, against the promise of a more fulfilling future, what gets played out is a game of loss and gain, presence and absence, which produces a quota of enjoyment in the present (McGowan, 2016). In reviewing the relevance of enjoyment as a political factor, Derek Hook (2017) notes that it would be incorrect to claim that enjoyment is unconscious, for it always includes an affective and bodily dimension. Both for Freud and Lacan, affects are not repressed but rather displaced; what is broken in fact is the link with their ideational representative or signifying function (Soler, 2016). What remains unconscious is not the enjoyment itself but the (ideological) function it plays. In the case of dating apps, the primary function is not that of enabling an embodied encounter but of producing a libidinal attachment to the process of looking for one.

The enjoyment generated by the match is thus a trait of the relationship that the subject has with the app itself by means of potential others, and not with potential others by means of the app. From this viewpoint, dating apps (and 
arguably apps in general) emerge as objects producing forms of affective attachment in and for themselves.

\section{Love Me, Tinder}

The words of most research participants betray an affective relationship with the app, made of interruptions and new beginnings, hope and frustration. They recall having gotten 'angry at Tinder' because it was 'not working' or because it was 'fake' or 'addictive'. They would then delete it only to reinstall it eventually, often as a result of a form of jealousy: the desire for the app being reactivated by the image of it with 'someone else', in a triangulation that constitutes a typical symbolic structure of desire (Fink, 2017).

Saul, an actor in his mid-twenties who studies in Bristol, summarises his relationship with Tinder as follows:

I downloaded it because I saw everybody had it, so I thought why not? I had kind of great expectations... But I don't know why it was never happening... I tried to change my profile, my bio, to make things work, but it didn't. I grew frustrated, and I deleted it. ... Then I went on tour and the director of the show was using Tinder all the time, getting a lot of dates... I thought ok it gotta work for me too, so I tried again...

Saul's desire to activate Tinder was triggered by the desire of others who were using it and supposedly getting what they wanted from it. He describes a difficult relationship in which things won't work and in which he had to change himself (the picture, the bio) in the aim of getting things right. But that was impossible, and he gave up: a radical break-up. When Saul saw Tinder with someone else ('somebody new'?), his desire for the app was re-ignited. Most users appear to have gone through a similar process in what some of them describe as an 'on and off relationship' with dating apps.

If we look at the ways in which Tinder is designed, we notice that it constantly speaks to us, demands, invites, incites. Tinder is relentlessly friendly and always available. If you don't open it for a while, it teases with its messages, reminding you that others are enjoying the swiping: 'Who are all these new people swiping in your area? Swipe to find out', or 'You have 313 new likes! Swipe to see if you like them back'. If you are ignoring it, the app reacts, trying to be flattering, ultimately to win you back, to have you touching it, enjoying it. It wants us. It wants us to be there, to do things. And, when a match occurs, Tinder is there to encourage and reassure ('You know they already want to talk to you, right?'); to play on a sense of urgency ('Send a message before your battery dies'); or shamelessly remind you how likeable it is ('Someone should create an app to meet cool people. Oh wait'). Tinder seduces - in its Latin 
meaning of 'leading' someone 'away' from themselves and towards the seducer - insofar as it constantly tries to hook and keep its users. This permissive and amicable way of addressing the subject disguises a super-egoic demand for active engagement which plays on our sense of guilt and inadequacy.

What is at stake is a seductive dynamic in which the app itself commands a form of enjoyment, articulating its own demand of being used and touched. The app functions both as a void that attracts an array of emotions, feelings and projections, and an object that ceaselessly syphons off our enjoyment; its existence depends less on its ability to 'deliver' a date than to keep us engaged in its ever-promising yet failure-ridden enjoyment circuits. As a matter of fact, in order to 'survive', the app needs to keep us desirous (i.e. dissatisfied) and, at the same time, libidinally attached to it (i.e. dependent on its enjoyment-boosts). Incidentally, this also holds as true from an industry viewpoint, for dating apps' business model needs users to be (constantly) in search of something in the app and not to find that something for good (love, sex or whatever else) outside of it.

\section{What Does the App Want?}

As our research findings suggest, dating apps entail a libidinal economy that operates independently of the app's obvious function of connecting individuals. What may seem eccentric uses of Tinder and dating apps in general are central to their success. What makes them 'effective' is the process in which they engage users, rather than the outcomes they produce. In a cultural atmosphere where having a dating life, and a desire oriented towards sex and love, becomes an imperative, the space for this desire to emerge is compromised. Bombarded with invitations and injunctions to live the 'swipe life' - to have more and better sex, more and healthier relationships, to experiment, to dare, to 'take it all' - we may face the question of how to confront the anxiety resulting from our failures to embody the happy individuals we are supposed to be. Dating apps may be used to tackle this issue, for they offer ways to engage with one's and the Other's desire without the necessity of an embodied encounter. The app acts as what teases and triggers, alludes and deludes, becoming a partner in its own right. And, crucially, this process generates a paradoxical (dis)satisfaction precisely because it plays out the impossibility of putting a stop to the endless metonymy of desire.

In these regards, it is revealing to see how dating apps accommodate the interchangeability and ineludible ephemerality of the object (cause) of desire whilst obfuscating the constitutional negativity that is linked to it. It is precisely in this dynamic that the reasons for the pervasiveness of dating apps may be found. The repetitive dynamic of swiping and matching replicates capitalism's logic of accumulation and its ever-renewed promise of total satisfaction through commodity consumption. It is when the promised object is relentlessly framed 
and lost, swiped and accumulated, that a quota of surplus enjoyment is produced, Since every time one misses the object, one is granted the possibility of a new boost as the encounter is re-staged at the level of fantasy.

It is important to stress that surplus enjoyment is not produced within the Freudian pleasure principle but should be situated in its 'beyond', that is, in the realm of sex and the drives (Zupančič, 2017). Indeed, sexual enjoyment implies a de-regulation of the pleasure principle, a disturbance of its homeostatic logic, which might cause tension or pain but also grants a surplus. As Zupančič (2008) argues, it is precisely when the organised system of pleasure (automaton) fails to work as it encounters a point of negativity in the Other, that a contingent surplus enjoyment (tyche) is produced. Put simply, we enjoy where something does not work.

Whilst often going unnoticed, this partial satisfaction is key in articulating users' engagement with the dating app. It is insofar as they hold the potential to endlessly (re)stage and disattend their promises that dating apps operate so effectively. Their effectiveness should therefore be praised not insofar as they may procure us the date they promised us but because they may become 'precious' libidinal objects despite failing to do so. We use dating apps to get access to a way of desiring another human being, and they allow us to do so by framing anonymous individuals, as well as our own selves, as desirable. But we may well end up involved in a fantasy scenario whereby the app itself functions as a 'stand in' for our potential partners, because, after all, what we relate to is the app. We act on it. We are acted upon by it. A seemingly paradoxical overturn: rather than relating to other persons by means of the app, we relate to the app my means of other persons.

\section{Conclusion: Towards a Disembodied Intimacy?}

In this article, we have taken dating apps as a case study to tackle the question of desire in digital societies. Combining ethnographic methods with Lacanian theories, we have offered an analysis of the psychic investment that characterises the relationship between dating apps and their users. Focusing on the microphysics of subjective enjoyment, we have shown that the success of dating apps cannot be reduced to their manifest purpose of organising dates. Rather, we argue that the primary function of dating apps is to support, hook and turn the subject's desire vis-à-vis the imperative to enjoy that characterises late capitalism. Certainly, an embodied encounter can happen, but this may be considered as a by-product of dating apps' operations rather than their core activity. From a media and cultural studies perspective, this may be understood as a psychoanalytic description of the app's 'stickiness' that contributes to identifying the ways in which dating apps participate in the late capitalist 
cooptation of desire, remediating values and practices associated with the realms of love and sex in datafied digital economies.

Recents observations on the use of dating apps during the Covid-19 lockdowns seem to offer further evidence in support of this argument. From the conception of dating apps as tools to source an embodied meeting with another person, it should follow that, once the latter is made impossible, dating apps become substantially useless. Therefore, during the weeks of lockdown in Spring 2020, one would expect a drop in dating apps' engagement. In fact, the opposite happened. In an article published on 9 May 2020, The Economist (2020) reported that, under lockdown conditions, users' engagement with dating apps has increased globally: 'During the worst week of China's epidemic, in late February, the average user of TanTan, a Chinese app, spent 30\% longer on the app than normal [. . .] [In the US] between late February and late March, the average length of a conversation on Tinder [. . .] surged by $25 \%$.'

These data can be explained by a range of factors that go well beyond the scope of our analysis, yet they further demonstrate that what hooks us to dating apps is not only the perspective of an embodied date. This may open up speculations about the significance of embodiment and its emotional burden. Is it that, once the body is out of the way, dating apps' users find a renewed ease in connecting to others? This depicts a culture that, rather than eagerly seeking sexual encounters, is more interested in avoiding them and finding alternative practices. An article published in Vogue provocatively suggests that, during lockdown, we might have discovered that 'sexting is better than the real thing' (Lord, 2020). Further research on this phenomenon may be crucial to tackle the politics of desire in digital societies.

\section{About the Authors}

Carolina Bandinelli is Assistant Professor in Media and Creative Industries at the University of Warwick. Her research focuses on emerging forms of subjectivity and sociality in digital media and creative industries, which she explores combining ethnographic methods with the analysis of symbolic and affective experiences.

Arturo Bandinelli is an independent researcher, filmmaker and training Lacanian psychoanalyst at the Centre for Freudian Analysis and Research in London. He has recently completed an MA in Psychosocial Studies at Birkbeck University, where he is due to start his $\mathrm{PhD}$ on Posthuman Sexuality in September 2021. In his intellectual and creative practices, he explores the relationship between subjectivity and otherness, gaze and identity, and sexual politics and bodies. 


\section{Notes}

1. For an exploration of enjoyment in Lacan's teaching, see Miller (2019); for discussions on enjoyment as a socio-cultural and political factor, see Žižek (1993) and Hook (2017).

2. We recognise a resonance between this part of our argument and the ways in which the concept of lathouse has been discussed in recent years (see, for instance, Voruz, 2010; Millar, 2018).

\section{References}

Ansari, A. and Klinenberg, E. (2015) Modern Romance. New York: Penguin Press.

Bauman, Z. (2003) Liquid Love: On the Frailty of Human Bonds. Cambridge, UK: Polity.

Beck, U. and Beck-Gernshein, E. (1990) The Normal Chaos of Love. London: Polity.

Beck, U. and Beck-Gernsheim, E. (2008) Global generations and the trap of methodological nationalism for a cosmopolitan turn in the sociology of youth and generation. European Sociological Review 25(1): 25-36.

Belton, P. (2018) Love and dating after the Tinder revolution. https://www.bbc.co.uk/ news/business-42988025, accessed 1 July 2020.

Bown, A. (2015) Enjoying It: Candy Crush and Capitalism. Winchester, UK: Zero Books.

boyd, D. (2014) It's Complicated: The Social Lives of Networked Teens. New Haven: Yale University Press.

Carpenter, C.J. and McEwan, B. (2016) The players of micro-dating: Individual and gender differences in goal orientations toward micro-dating apps. First Monday 21(5). https:// firstmonday.org/ojs/index.php/fm/article/view/6187, accessed 1 March 2021.

Comunello, F. and Parisi, L. (2020) Dating apps. In: K. Ross, I. Bachmann, V. Cardo, S. Moorti and M. Scarcelli (eds) The International Encyclopedia of Gender, Media, and Communication. https://doi.org/10.1002/9781119429128.iegmc007.

Davies, C., Coleman, J.C. and Livingstone, S.M. (2014) Digital Technologies in the Lives of Young People. Abingdon, Oxon: Routledge.

De Rougemont, D. (1983) Love in the Western World. Princeton: Princeton University Press.

Deuze, M. (2011) Media life. Media, Culture \& Society 33(1): 137-48.

De Wiele, C. and Campbell, F. (2019) From swiping to ghosting: Conceptualising rejection in mobile dating. In: A. Hetsroni and M. Tuncez (eds) It Happened on Tinder: Reflections and Studies on Internet-infused Dating. Amsterdam: Institute of Network Cultures, pp. 158-76.

Economist. (2020) Fewer when you hold me tight. Casual sex is out, companionship is in. Lockdowns are forcing singletons to embrace emotional intimacy. 9 May. https://www. economist.com/international/2020/05/09/casual-sex-is-out-companionship-is-in, accessed 1 July 2020.

Ellison, N., Hancock, J.T. and Toma, C.L. (2011) Profile as promise: A framework for conceptualizing veracity in online dating self-presentations. New Media \& Society 14(1): 45-62. 
Fink, B. (2017) Lacan on Love: An Exploration of Lacan's Seminar VIII, Transference. Cambridge, UK: Polity.

Flisfeder, M., Willis, L.-P. and Žižek, S. (2016) Žižek and Media Studies: A Reader. Basingstoke: Palgrave Macmillan.

Freud, S. (1908/1959) 'Civilized' sexual morality and modern nervous illness. Standard Edition 9. London: Hogarth Press, pp. 177-204.

Freud, S. (1930/1961) Civilization and its Discontents. Standard Edition 21. London: Hogarth Press, pp. 57-146.

Frith, H. (2015) Orgasmic Bodies: The Orgasm in Contemporary Western Culture. Basingstoke: Palgrave Macmillan.

Frosh, S. (2010) Psychoanalysis Outside the Clinic: Interventions in Psychosocial Studies. Basingstoke: Palgrave Macmillan.

Gibbs, J., Ellison, N. and Lai, C. (2011) First comes love, then comes Google: An investigation of uncertainty reduction strategies and self-disclosure in online dating. Communication Research 38(1): 70-100.

Giddens, A. (1992) The Transformation of Intimacy: Sexuality, Love and Eroticism in Modern Societies. London: Polity.

Heino, R., Ellison, N. and Gibbs, J. (2010) Relationshopping: Investigating the market metaphor in online dating. Journal of Social and Personal Relationships 27(4): 427-47.

Hobbs, M., Owen, S. and Gerber, L. (2008) Liquid love? Dating apps, sex, relationships and the digital transformation of intimacy. Journal of Sociology 53(2): 271-84.

Hollway, W. and Jefferson, T. (1997) Eliciting narrative through the in-depth interview. Qualitative Inquiry 3(1): 53-70.

Hook, D. (2008) Articulating psychoanalysis and psychosocial studies: Limitations and possibilities. Psychoanalysis, Culture \& Society 13(4): 397-405.

Hook, D. (2017) What is "enjoyment as a political factor"? Political Psychology 38(4): 605-20.

Illouz, E. (2011) Why Love Hurts: A Sociological Explanation. London: Polity.

Johanssen, J. (2019) Psychoanalysis and Digital Culture: Audiences, Social Media, and Big Data. New York/London: Routledge.

Kim, S., Baek, T.H., Kim, Y.-K. and Yoo, K. (2016) Factors affecting stickiness and word of mouth in mobile applications. Journal of Research in Interactive Marketing 10(3): 177-92.

Lacan, J. (1999) The Seminar of Jacques Lacan. Book XX, On Feminine Sexuality, The Limits of Love and Knowledge. Edited by J-A. Miller. Translated by B. Fink. New York: Norton.

Lacan, J. (2007) The Seminar of Jacques Lacan. Book XVII, The Other Side of Psychoanalysis. Edited by J-A. Miller. Translated by R. Grigg. New York: Norton.

Lord, A. (2020) Will lockdown easing prove that sexting is better than the real thing? https://www.vogue.co.uk/arts-and-lifestyle/article/sexting, accessed 10 March 2021.

Marcuse, H. (1998) Eros and Civilization: A Philosophical Inquiry into Freud. London: Routledge.

McGloin, R. and Denes, A. (2016) Too hot to trust: Examining the relationship between attractiveness, trustworthiness, and desire to date in online dating. New Media \& Society 20(3): 919-36. 
McGowan, T. (2004) The End of Dissatisfaction? Jacques Lacan and the Emerging Society of Enjoyment. Albany, New York: State University of New York Press.

McGowan, T. (2016) Capitalism and Desire: The Psychic Cost of Free Markets. New York: Columbia University Press.

Millar, I. (2018) Ex-machina: Sex, knowledge and artificial intelligence. Psychoanalytische Perspecteven 36(4): 447-67.

Miller, J.-A. (2019) Six Paradigms of Jouissance. Edited by R. Litten. (Psychoanalytical Notebooks No. 34). London: London Society of the New Lacanian School (NLS).

Morozov, E. (2013) To Save Everything, Click Here: The Folly of Technological Solutionism. London: Allen Lane.

Papacharissi Z. (2011) A Networked Self: Identity, Community and Culture on Social Network Sites. New York: Routledge.

Parker, I. (2010) Psychosocial studies: Lacanian discourse analysis negotiating interview text. Psychoanalysis, Culture \&o Society 15(2): 156-72.

Ranzini, G. and Lutz, C. (2017) Love at first swipe? Explaining Tinder self-presentation and motives. Mobile Media \& Communication 5(1): 80-101. doi: https://doi.org/10. 1177/2050157916664559.

Reich, W. (1974) The Sexual Revolution. New York: Farrar, Straus \& Giroux.

Roseneil, S. (2006) The ambivalences of Angel's “arrangement”: A psychosocial lens on the contemporary condition of personal life. The Sociological Review 54(4): 847-69.

Salecl, R. (2010) The Tyranny of Choice. London: Profile.

Sharabi, L. and Caughlin. J. (2018) Deception in online dating: Significance and implications for the first offline date. New Media and Society. doi: https://doi.org/10. $1177 / 1461444818792425$.

Soler, C. (2016) Lacanian Affects: The Function of Affect in Lacan's Work. London; New York: Routledge.

Statista (2020) Online dating - worldwide I Statista market forecast [online]. https://www. statista.com/outlook/372/100/online-dating/worldwide, accessed 1 January 2021.

Sumter S.R. and Vandenbosch, L. (2019) Dating gone mobile: Demographic and personality-based correlates of using smartphone-based dating applications among emerging adults. New Media \& Society 21(3): 655-73.

Turkle, S. (2011) Alone Together: Why we Expect More from Technology and Less from Each Other. New York: Basic Books.

Vighi, F. (2015) Ontology of crisis and Lacan's discourse of the capitalist. Psychoanalysis, Culture \& Society 20(1): 1-19.

Voruz, V. (2010) Psychoanalysis at the time of the posthuman: Insisting on the outsidesense. Paragraph 33(3): 423-43.

Wade, L. (2017) American Hookup: The New Culture of Sex on Campus. New York: W.W. Norton.

Ward, J. (2016) Swiping, matching, chatting: Self-presentation and self-disclosure on mobile dating apps. Human IT 13(2): 81-95.

Zichermann, G. and Cunningham, C. (2011) Gamification by Design: Implementing Game Mechanics in Web and Mobile Apps. Sebastopol, CA: O'Reilly Media.

Žižek, S. (1993) For They Know Not What They Do: Enjoyment as a Political Factor. London; New York: Verso. 


\section{Bandinelli and Bandinelli}

Žižek, S. (1997) The Plague of Fantasies. London: Verso.

Žižek, S. (2005) The Metastases of Enjoyment: Six Essays on Women and Causality. London: Verso.

Zupančič, A. (2008) The Odd One In: On Comedy. Cambridge, MA: MIT Press. Zupančič, A. (2017) What is Sex. Cambridge, MA: MIT Press.

Publisher's Note Springer Nature remains neutral with regard to jurisdictional claims in published maps and institutional affiliations. 